\title{
A TECITURA FILOSÓFICA DE WALTER BENJAMIN E OS ENTRELAÇAMENTOS ENTRE BELEZA E VERDADE
}

Mariana Andrade

\begin{abstract}
RESUMO
O presente texto propõe uma investigação sobre a relação entre verdade e beleza na filosofia de Walter Benjamin. Para tal, propomos um caminho investigativo a partir do conceito do sem-expressão [Ausdrucklos], elaborado no ensaio. As afinidade eletivas de Goethe de 1922, no contexto das discussões sobre a concepção de beleza e sua associação à aparência. A seguir, desembocaremos no prefácio críticoepistemológico do livro Origem do drama barroco alemão [Ursprung des deutschen Trauerspiels] escrito em 1925, no qual o filósofo desenvolve, de maneira explícita, a relação entre verdade e beleza. Durante todo o percurso, estaremos especialmente atentos ao modo como a noção de apresentação [Darstellung] opera um papel fundamental na filosofia de Walter Benjamin e como essa questão está profundamente articulada à defesa do caráter linguístico e histórico do pensamento filosófico e de uma dimensão estética do exercício filosófico.
\end{abstract}

Palavras-chave: beleza; aparência; verdade; sem-expressão; apresentação.

\section{THE PHILOSOPHICAL TISSUE OF WALTER BENJAMIN AND THE WEAVING BETWEEN BEAUTY AND TRUTH}

\begin{abstract}
The present paper proposes an investigation on the relation between truth and beauty in the philosophy of Walter Benjamin. For this end, we propose an investigative starting with the concept of the expressionless [Ausdrücklos], elaborated in the essay Goethe's Elective Affinities of 1922, in the context of the discussions about the conception of beauty and its association with semblance. Then we get in the "Epistemo-Critcal Prologue" of his work The Origin of German Tragic Drama [Ursprung des deutschen Trauerspiels] written in 1925, in which the philosopher explicitly develops the relationship between truth and beauty. During this pathway, we will be especially attentive to the way in which the notion of presentation [Darstellung] plays a fundamental role in Walter Benjamin's thought and how this question is deeply articulated to a defense of the linguistic and historical character of philosophical thought and of an aesthetic dimension of philosophical practice.
\end{abstract}

Keywords: beauty; semblance; truth; expressionless; presentation.

Doutoranda em Filosofia pela Universidade Federal de Goiás (UFG). Brasileira, residente em Goiânia, Goiás. E-mail: mariana.andrade.luz@gmail.com 
"E, dado que a beleza precisa ser diariamente estilhaçada para permanecer bela..." Virginia Woolf

O pensamento de Walter Benjamin pode ser chamado, se quisermos um nome, de "saber dos limiares" [Schwellenkunde]. A bela expressão, cunhada por Menninghaus para caracterizar o legado de Benjamin, pode ser tomada como chavemestra de leitura da obra benjaminiana. A filosofia de Benjamin se desenvolve nas entranhas da estética e da crítica literária e, ao mesmo tempo, parece não se conformar com o conforto do lugar de pertencimento. A força crítica de seu pensamento está, por essa razão, na criação desses espaços-do-entre: margens do pensamento em que os limiares entre filosofia e arte se cruzam criando lugares de passagem para a reflexão filosófica. No presente texto propomos investigar os limiares entre arte e filosofia no pensamento benjaminiano a partir do exame da relação entre verdade e beleza estabelecida pelo filósofo.

No prefácio crítico-epistemológico de 1925, Benjamin nos apresenta uma reflexão sobre a relação entre verdade e beleza realizada a partir de uma interpretação do diálogo Banquete de Platão. No texto As afinidades eletivas de Goethe, escrito um pouco antes da obra sobre o Trauerspiel', em 1922, Benjamin expõe discussões sobre

\footnotetext{
1 Diversos tradutores, comentadores e estudiosos de Benjamin divergem e propõem alternativas para a tradução de Trauerspiel. As duas traduções para o português publicadas dessa obra possuem o termo traduzido de formas diferentes: Rouanet (BENJAMIN, 1984) traduz como "drama barroco" e Barrento (BENJAMIN, 2013) adota "drama trágico". Haroldo Campos (1992) sugere o neologismo "lutilúdico", buscando etimologicamente uma aproximação na tradução em português. Spiel refere-se a jogo, espetáculo, folguedo e Trauer designa tristeza, não de forma geral, mas a tristeza provocada pela morte, isto é, o estado do luto. Trauerspiel, utilizado por Benjamin para caracterizar o teatro barroco alemão seria, então, uma encenação do luto. Romero de Freitas (2003), por sua vez, sugere a opção "drama de luto". Pela dificuldade da tradução e pela insuficiência detectada nas alternativas disponíveis, optaremos por designar o termo no original, como foi a opção da tradutora Carola Pivetta (BENJAMIN, 2012).
}

Doutoranda em Filosofia pela Universidade Federal de Goiás (UFG). Brasileira, residente em Goiânia, Goiás. E-mail: mariana.andrade.luz@gmail.com 
a questão da beleza e sua relação com a aparência, e é no contexto dessas discussões que o filósofo elabora o seu conceito do sem-expressão [Ausdrucklos]: esse conceito opera uma função fundamental na configuração que Benjamin estabelece entre beleza, aparência e verdade. Tendo em vista que essas questões desenvolvidas no ensaio sobre o romance de Goethe podem nos oferecer um importante suporte teórico para uma melhor compreensão da relação que Benjamin estabelece entre verdade e beleza no prefácio, enveredaremos nossa investigação por esse caminho.

\section{Sobre a relação entre beleza e aparência: o sem-expressão}

Em As afinidades eletivas de Goethe, no cenário da discussão sobre a possibilidade da forma da obra de arte permitir a aparecimento da verdade, isto é, em termos propriamente benjaminianos, o aparecimento do teor de verdade no teor material, Benjamin remete a discussão para a questão do modo como a beleza é concebida. Antes de adentramos a questão da beleza propriamente dita, é importante entendermos o contexto em que essa discussão é desenvolvida e os conceitos que estão em jogo, no caso, os conceitos de teor de verdade [Wahrheitsgehalt] e teor material ${ }^{2}$ [Sachgehalt] desenvolvidos pelo filósofo nesse mesmo texto, em relação às especificidades da tarefa da crítica e do comentário.

Benjamin relaciona a atividade do comentário ao teor material da obra: o comentário seria a análise detalhada do material de uma obra, um trabalho de investigação histórica e filológica. A elaboração crítica de uma obra, por sua vez, seria capaz de revelar o teor de verdade de uma obra, isto é, aquilo que está para além da sua condição histórica propriamente finita e temporalmente limitada. A crítica, todavia,

2 Preferimos a opção da tradutora Mônica Bornebusch (BENJAMIN, 2009) por traduzir Gehalt como teor e não como conteúdo como faz Rouanet (BENJAMIN, 1984). Segundo Gagnebin (2011), conteúdo seria uma tradução para Inhalt e remeteria à oposição entre forma e conteúdo que Benjamin evita ao usar Gehalt. Sachgehalt, por sua vez, é traduzido por Bonerbusch como teor factual enquanto Rouanet utiliza material e não factual. Mantemos essa opção de Rouanet para evitar o risco de remissão ao sentido de factualidade e não de materialidade, confusão desnecessária alertada por Gagnebin.

Doutoranda em Filosofia pela Universidade Federal de Goiás (UFG). Brasileira, residente em Goiânia, Goiás. E-mail: mariana.andrade.luz@gmail.com 
só consegue realizar essa sua tarefa a partir de uma imersão no teor material para, então, ser capaz fazer aparecer o teor de verdade. Nesse sentido, toda elaboração crítica necessita do exercício prévio do comentário já que o teor de verdade de uma obra só aparece na sua configuração concreta. Benjamin evidencia nessa imbricação entre crítica e comentário, teor material e teor verdade, a relação entre verdade e história: por mais que a verdade remeta à uma dimensão atemporal, ela é constituída histórica e linguisticamente e só pode ser apreendida através da imersão nos elementos temporais e materiais. Por ora, deixemos de lado essas categorias mas, como veremos mais adiante, essa discussão será relevante para a compreensão da relação entre verdade e beleza desenvolvida no prefácio do Trauerspielbuch. Voltemos, então, à investigação da concepção de beleza em As afinidades eletivas de Goethe.

No ensaio em questão, Benjamin problematiza a redução da beleza à aparência e procura expor uma concepção de beleza não restrita à noção da bela aparência [schöner Schein]. Ao desenvolver a questão da concepção de beleza, o alvo do problema enfrentado por Benjamin é a identificação entre beleza e aparência. $O$ filósofo inicia a discussão da relação entre beleza e aparência afirmando que "tudo o que é essencialmente belo está ligado sempre e de modo essencial, mas em graus infinitamente diferenciados, à aparência" (BENJAMIN, 2009, 110). Para Benjamin, a relação entre beleza e aparência manifesta-se com maior intensidade na beleza corporalmente viva, isto é, na aparência do corpo vivo. Assim, Benjamin retoma e reelabora uma tradição filosófica que remete à Platão na qual a beleza é pensada a partir de sua relação com a aparência e a vitalidade do corpo.

Para o filósofo, a aparência do belo está relacionada à aparência do corpo vivo, isto é, a bela aparência está essencialmente ligada à aparência da vivacidade. Contudo, para Benjamin, a beleza não pode ser reduzida somente ao aspecto da bela aparência. É por esta razão que, ao caracterizar a obra de arte e o trabalho da crítica de arte, Benjamin evidencia o seu aspecto contrário, negativo e destrutivo, capaz de romper com a bela aparência. Para Benjamin, há um momento destrutivo próprio da arte em que a vida aparece como que paralisada ou petrificada na obra de arte. Esse momento revela uma força contrária à beleza viva e é este elemento que impede que 
a obra de arte se reduza à mera bela aparência. A crítica também possui esse caráter destruidor da bela aparência já que, para Benjamin, a tarefa da crítica seria justamente um trabalho de mortificação da bela aparência da obra de arte ${ }^{3}$. Ao pensar a beleza não reduzida à bela aparência, a dimensão do vivo é tomada por Benjamin em toda sua amplitude histórica e isso inclui o horizonte da morte: a beleza não é apenas a vivacidade da aparência mas também possui uma negatividade essencial que é constitutiva da própria beleza. Como veremos, essa força negativa capaz de romper com a bela aparência será caracterizada por Benjamin como o sem-expressão.

Para Benjamin, beleza e aparência estão relacionadas, mas não podem ser definidas como uma e a mesma coisa, isto é, a beleza não pode ser identificada com a aparência. O filósofo afirma "a própria beleza não é, como ensinam os filosofemas banais, aparência" (BENJAMIN, 2009, 111). Esses "filosofemas banais" são ilustrados por Benjamin na afirmação de Solger segundo a qual a beleza seria a verdade visível, afirmação esta que é qualificada pelo filósofo como um "barbarismo filosófico". Benjamin critica e contrapõe-se à toda corrente da tradição estética alemã, exemplificada pela afirmação de Solger, que elabora a relação entre verdade e beleza concebendo a beleza como o aparecimento ou manifestação visível da verdade. Segundo Benjamin, esse pensamento distorce e banaliza a relação filosófica entre verdade e beleza justamente por desenvolver seu raciocínio apoiado na redução da beleza unicamente à aparência. Benjamin critica o fundamento último desse pensamento que, segundo o filósofo, seria a pressuposição da possibilidade de desvelamento da verdade do belo. Para Benjamin, a verdade da beleza não pode ser des-velada uma vez a essência da beleza exige que ela só se mostre veladamente. A verdade da beleza não é um aparecimento de sua essência já que, para o filósofo, a essência mesma da beleza não possui um aparecimento sensível: essência da beleza está no modo velado da sua manifestação. Para ilustrar essa característica essencial da beleza, o filósofo se vale da imagem metafórica do envoltório e do objeto envolvido. Diz Benjamin:

3 No livro sobre o Trauerspie/ Benjamin é enfático: "A crítica é mortificação das obras" (BENJAMIN, 1984, 203).

Doutoranda em Filosofia pela Universidade Federal de Goiás (UFG). Brasileira, residente em Goiânia, Goiás. E-mail: mariana.andrade.luz@gmail.com 


\begin{abstract}
A beleza não é aparência, não é um envoltório para encobrir outra coisa. Ela mesma não é aparição, mas sim inteiramente essência - uma essência, porém, que se mantém, em impregnação essencial, idêntica a si mesma apenas sob velamento. Por isso, pode ser que a aparência iluda por toda parte: a bela aparência é o envoltório lançado sobre aquilo que é necessariamente o mais velado. Pois o belo não é nem o envoltório nem o objeto velado, mas sim o objeto em seu envoltório. (...) Diante, portanto, de todo belo, a ideia do desvelamento converte-se naquela da impossibilidade de desvelamento. Essa é a ideia da crítica de arte. A tarefa da crítica de arte não é tirar o envoltório, mas antes elevar-se à contemplação do belo mediante a percepção mais exata do envoltório enquanto envoltório (BENJAMIN, 2009, 112).
\end{abstract}

Para Benjamin a beleza não é a mera aparência, isto é, não é o envoltório que cobre o objeto, mas também não é o objeto desvelado: a beleza é a unidade que se forma entre o envoltório e aquilo que está velado pelo envoltório. Por esta razão, a beleza é, essencial e simultaneamente, tanto o envoltório quanto aquilo velado por ele. A essência da beleza exige que ela só apareça de forma velada pois, para Benjamin, o fundamento ontológico da beleza está no mistério. Aqui está em jogo uma concepção metafísica do belo como mistério em Benjamin. Como consequência dessa concepção de beleza tem-se a impossibilidade do desvelamento: a ideia da beleza não pode ser desvelada. Há somente a possibilidade de revelação do mistério dessa ideia uma vez que "a beleza não torna a ideia visível, mas sim o seu segredo" (BENJAMIN, 2009, 113). Atrelado a esse modo de conceber a beleza e à afirmação da relação de não identidade entre beleza e aparência, o conceito do sem-expressão ocupa um lugar fundamental na reflexão benjaminiana sobre o belo. Diz o filósofo:

\begin{abstract}
Embora em contraposição à aparência, o sem-expressão mantém com ela uma relação de tal modo necessária, que justamente o belo, ainda que ele mesmo não seja aparência, deixa de ser essencialmente belo quando a aparência desaparece dele. Pois a aparência pertence ao essencialmente belo enquanto envoltório, e o fato de que a beleza como tal só apareça naquilo que está velado mostra-se como sua lei essencial (BENJAMIN, 2009, 111).
\end{abstract}

Para Benjamin, em sua essência a beleza possui uma negatividade intrínseca capaz de abalar o seu aspecto de mera aparência. Na obra de arte, essa negatividade se manifesta como uma força que rompe com a bela aparência e é nomeada por Doutoranda em Filosofia pela Universidade Federal de Goiás (UFG). Brasileira, residente em Goiânia, Goiás. E-mail: mariana.andrade.luz@gmail.com 
Benjamin como o sem-expressão. A beleza não pode ser separada da aparência, mas é justamente a força do sem-expressão que, na arte, impossibilita que aparência e essência da beleza se confundam e se identifiquem uma com a outra. $O$ semexpressão figura, então, operando um papel crucial na relação entre aparência e beleza configurada por Benjamin. O filósofo afirma que "a aparência, contudo, não engloba a essência da beleza. Esta, pelo contrário, indica mais profundamente aquilo que na obra de arte, contrapondo-se à aparência, pode ser designado como o semexpressão" (BENJAMIN, 2009, 111).

O sem-expressão é caracterizado por Benjamin como sendo uma categoria da linguagem e das artes e o filósofo vislumbra a definição do sem-expressão a partir de uma aproximação com a noção de cesura de Hölderlin. A noção de cesura é desenvolvida por Hölderlin no contexto de sua teoria da tragédia e, para Benjamin, a cesura descreveria de modo mais próximo a definição do sem-expressão. Em Observações sobre Édipo, Hölderin descreve um movimento reflexivo na construção do texto que marca uma interrupção na sequência do discurso, chamada de cesura. Esse movimento é apontado por Hölderin no Édipo rei de Sófocles e caracterizado como uma interrupção contrarrítimica do discurso, isto é, como uma quebra ou suspensão do ritmo do desenvolvimento poético em que há uma reversão no encadeamento contínuo da ação no discurso. Na passagem citada por Benjamin ${ }^{4}$, Hölderin descreve o modo como a cesura interrompe o encadeamento linear das representações no discurso poético e ao romper com o fluxo de construção das representações, a cesura cria como que uma rachadura ou um rasgo na construção discursiva e é através dessa rachadura que o movimento da cesura revela o próprio trabalho da construção artística do discurso. Ao quebrar a continuidade do desenvolvimento discursivo, a representação é arrancada de sua função representacional, isto é, deixa de exercer o papel de um conteúdo representado no

4 A passagem de Hölderin citada por Benjamin (2009, 93): "O transporte trágico é, na verdade, vazio e o mais desvinculado possível. - Desse modo, na sequência rítmica das representações em que o transporte se apresenta, torna-se necessário isso que se denomina na métrica de cesura, a palavra pura, a interrupção contrarrítmica, para fazer frente à mudança rápida das representações em seu ponto mais alto, de tal maneira que apareça não mais a mudança da representação, mas sim a própria representação".

Doutoranda em Filosofia pela Universidade Federal de Goiás (UFG). Brasileira, residente em Goiânia, Goiás. E-mail: mariana.andrade.luz@gmail.com 
discurso e se expõe desnudada enquanto representação mesmo: explicita o próprio mecanismo representacional do discurso deixando à mostra processo de feitura do próprio trabalho artístico.

O sem-expressão é, então, uma força negativa contrária à aparência e uma potência violenta capaz de romper com o aspecto totalizador e harmônico da bela aparência na obra de arte. A bela aparência está relacionada ao aspecto de uma totalidade harmônica e perfeita da obra de arte. A bela aparência da obra de arte constitui essa aparência de totalidade absoluta, porém, para Benjamin, essa totalidade é apenas aparente sendo, portanto, uma totalidade falsa e enganadora. $O$ semexpressão é justamente aquilo que é capaz de romper a bela aparência e, por isso, destruir essa falsa aparência de totalidade. Nas palavras do filósofo:

\begin{abstract}
O que põe termo a essa aparência, o que prescreve o movimento e obsta a harmonia é o sem-expressão. (...) É o sem-expressão que destrói aquilo que ainda sobrevive em toda aparência bela como herança do caos: a totalidade falsa, enganosa - a totalidade absoluta. Só o sem-expressão consuma a obra que ele despedaça, fazendo dela um fragmento do mundo verdadeiro, torso de um símbolo (BENJAMIN, 2009, 92).
\end{abstract}

Ao irromper com o aspecto da mera aparência o sem-expressão vincula a beleza à verdade, segundo Benjamin (2009, 92) "no sem-expressão aparece o poder sublime da verdade". Essa relação entre verdade e beleza será desenvolvida por Benjamin no prefácio crítico-epistemológico, como veremos na sequência desse trabalho. Interessa-nos aqui a referência ao sublime e sua relação com o semexpressão. Os estudos de Kangussu (1999a e 1999b) nos oferecem uma interessante leitura dos rastros do sublime kantiano no conceito do sem-expressão de Benjamin. Kangussu aponta no sem-expressão de Benjamin afinidades com o sublime kantiano: a força do sem-expressão aponta para uma potência que ultrapassa qualquer possibilidade de expressão remetendo à dimensão do inexprimível assim como a experiência estética do sublime em Kant. O sublime é definido, por Kant, pelo seu caráter violento e negativo, o sem-expressão de Benjamin também traz consigo esses mesmos aspectos. Em uma das referências à Kant, no texto das Afinidades eletivas de Goethe, Benjamin $(2009,113)$ afirma que o caráter relacional é o fundamento da 
beleza para o filósofo de Königsberg. Segundo Kangussu (1999b, 161), essa seria uma forte afinidade entre os filósofos pois, assim como Kant, Benjamin também fundamenta a beleza não em um objeto mas em uma relação, relação esta que é descrita por ela como a "paradoxal relação do homem com o sem-expressão".

As afinidades que o sem-expressão possui com o sublime kantiano não são difíceis de notar, quando colocados lado-a-lado esses traços comuns se tornam visíveis e podem ser delineados sem grandes dificuldades. Todavia, do mesmo modo como as afinidades podem ser notadas, também diferenças podem ser percebidas e problematizadas. $^{5}$ É interessante notar que o sublime aparece, nesse contexto em Benjamin, caracterizando a potência do sem-expressão. Essa força negativa é contrária à aparência, mas pertence à própria beleza. Desse modo, diferentemente da tradição do sublime, em Benjamin, o sublime, enquanto força de potência negativa do sem-expressão, não aparece em relação de oposição à beleza, como em Burke e Kant, mas como um componente próprio da beleza. Assim, o parentesco pode ser delineado, mas não há uma identidade perfeita ou uma continuidade exata de uma certa tradição. Todavia, ainda mais frutífero que provar grau de precisão do parentesco é questionar o que esse parentesco pode nos indicar, como faz Kangussu. $\mathrm{Na}$ tentativa de investigar conceitualmente a beleza, as reflexões estéticas, tanto de Kant como de Benjamin, apontam para a dimensão do inexprimível ou do semexpressão. Kangussu interpreta nessa afinidade os seguintes indícios:

\begin{abstract}
Em Benjamin e em Kant, a beleza e a arte levam a razão a fazer uma autoscopia, e perceber que o fundamento que deseja alcançar está fora dos limites lógicos. Não se trata de cair no irracionalismo, porque o fato de perceber limites e, mais ainda, de colocar o fundamento do conhecimento além desses limites, significa que, de alguma maneira, eles já foram ultrapassados. Isto é, que a razão ampliou seu território como racionalidade estética tornando possível o trânsito entre dois territórios distintos, porém inseparáveis. Se aceitarmos que 'racionalidade estética' não é uma contradição em termos, vamos precisar de uma expressão filosófica em que sensível e inteligível, conteúdo e forma sejam um (KANGUSSU, 1999a, 171172).
\end{abstract}

\footnotetext{
5 Gatti $(2009,72)$ alerta para o fato de que o sem-expressão é um elemento próprio da ideia de beleza em Benjamin e, por isso, o sublime não aparecia opondo a beleza, mas seria um componente da beleza. Esta seria uma distinção entre Benjamin e a tradição do sublime.
}

Doutoranda em Filosofia pela Universidade Federal de Goiás (UFG). Brasileira, residente em Goiânia, Goiás. E-mail: mariana.andrade.luz@gmail.com 
Em Benjamin, esse caminho aberto pela racionalidade estética culmina na exigência da reflexão sobre a expressão filosófica através da defesa da filosofia enquanto exercício da apresentação [Darstellung] ${ }^{6}$. Assim como a beleza não se restringe à aparência também a apresentação pode ser confundida com a aparência. A apresentação extrapola o âmbito da aparência e evidencia a possibilidade da apresentação da verdade por meio do exercício da expressividade filosófica. A filosofia como apresentação é a reivindicação da tarefa filosófica enquanto exercício e tentativa permanente. A apresentação marca a tarefa da filosofia como sendo o esforço filosófico contínuo da tentativa de elaborar pela linguagem aquilo que está para além do que pode ser dito discursivamente: esforço de tentar dizer justamente o que não consegue ser dito, o esforço filosófico de apresentar através dos conceitos aquilo que extrapola a linguagem conceitual.

Benjamin escreve que "o mistério é o momento em que aquele se ergue do domínio de sua linguagem própria e penetra num domínio mais elevado e inatingível para ela. Por isso, ele jamais pode expressar-se em palavras, mas sim única e exclusivamente na apresentação [Darstellung]" (BENJAMIN, 2009, 120) [Tradução modificada] $]^{7}$. O mistério do sem-expressão impele a filosofia da apresentação a encarar e explorar os seus próprios limites, sem mascarar mas também sem se

6 Os dois tradutores do Trauerspielbuch de Benjamin publicadas em português, Barrento (BENJAMIN, 2013) e Rouanet (BENJAMIN, 1984), traduzem a palavra Darstellung utilizada por Benjamin como "representação". Gagnebin (2014) discute brevemente o sentido da palavra e indica que o termo deve ser traduzido por apresentação ou exposição, afastando a opção de traduzi-la por representação, porque remeteria ao sentido clássico do processo de representação mental de objetos exteriores ao sujeito, quando é justamente dessa tradição da filosofia da representação que Benjamin está se contrapondo. Para uma discussão pormenorizada sobre esse conflito de tradução e uma análise histórico-conceitual da diferenciação entre Darstellung (apresentação) e Vorstellung (representação), ver o estudo realizado na minha dissertação de mestrado intitulada "Os rastros de uma travessia: $A$ filosofia da (na) apresentação", na qual desenvolvo uma pesquisa sobre a centralidade da Darstellung (apresentação) enquanto método filosófico em Benjamin.

${ }^{7}$ A tradutora Mônica Bornebusch verte Darstellung (BENJAMIN, 1991b, 201) como representação na edição publicada desse texto de Benjamin em português (BENJAMIN, 2009). Do mesmo modo como fizemos com a tradução de Rouanet do prefácio do Trauerspielbuch, optamos pela modificação da tradução. Todas as traduções da palavra Darstellung serão modificadas para "apresentação" durante esse artigo. Cabe mencionar, ainda, as traduções da palavra alemã Darstellung para outras línguas, além do português. A tradução inglesa da obra de Benjamin, de John Osborne (BENJAMIN, 2003), utiliza representation. A tradução para o espanhol de Carola Pivetta (BENJAMIN, 2012), diferentemente, opta pela tradução como exposición. Somente esta última, portanto, estaria de acordo com a observação de Gagnebin (2014) segundo a qual Darstellung não deve ser traduzida por representação e sim por apresentação ou exposição.

Doutoranda em Filosofia pela Universidade Federal de Goiás (UFG). Brasileira, residente em Goiânia, Goiás. E-mail: mariana.andrade.luz@gmail.com 
resignar pelo inalcançável de sua busca. Ao se deparar com a dimensão do inexprimível, isto é, daquilo que não possui expressão, a filosofia vê-se obrigada a encarar sua própria negação e fazer dela elemento para a sua própria expressão: a fragilidade de seu caráter sempre provisório e incompleto se transforma em motor que põe em movimento o fazer filosófico nutrindo e renovando o estímulo para a ousadia de novas e diferentes tentativas. Ela não é índice de impossibilidade ou desistência, mas faz com que a filosofia se confronte com a necessidade de renovação constante de si mesma. Sua incompletude é também sua fertilidade: a filosofia sobrevive dessa sua abertura e a apresentação é o campo sempre aberto para as possibilidades infinitas da expressão filosófica.

\section{Sobre a relação entre verdade e beleza: a apresentação}

No prefácio crítico-epistemológico, Benjamin se vale de uma interpretação do Banquete de Platão para explicitar a relação entre a verdade e a beleza, isto é, o filósofo configura o caráter relacional entre verdade e beleza a partir de uma leitura da obra platônica. Desse modo, Benjamin retoma a discussão entre verdade e beleza presente em Platão reelaborando-a para, desse modo, expor o modo próprio como ele concebe a relação entre verdade e beleza. Ao comentar a leitura que Benjamin faz de Platão no prefácio, Gagnebin (2014) nos oferece uma ponderação que pode servir como um alerta a ser colocado de antemão: Benjamin faz uma leitura peculiar e bastante ousada do Banquete e utiliza os conceitos platônicos e algumas das ideias que Platão desenvolve nessa obra sem, contudo, postular a mesma hierarquia ontológica.

Antes de recorrer ao Banquete para discutir a relação entre verdade e beleza, Benjamin faz referência à doutrina platônica das ideias no contexto de sua argumentação sobre a distinção entre verdade e conhecimento. O filósofo afirma que "a tese de que o objeto do saber não coincide com a verdade revela-se, sempre de novo, uma das mais profundas intuições da filosofia original, a doutrina platônica das idéias" (BENJAMIN, 1984, 52). Para Benjamin, a verdade não pode ser entendida 
como algo produzido na e pela consciência a partir da relação intencional do sujeito com o objeto: essa estrutura diz respeito ao conhecimento e não à verdade. $\mathrm{A}$ verdade, para o filósofo, possui um estatuto ontológico próprio sendo, por isso, considerada como um ser. Nesse sentido, Benjamin concebe a verdade como tendo uma existência anterior e separada da consciência intencional do sujeito do conhecimento. Benjamin localiza na teoria das ideias de Platão o estabelecimento de uma distinção entre verdade e conhecimento e, como consequência dessa diferenciação, o reconhecimento da condição ontológica da verdade. Diz o filósofo:

\footnotetext{
A distinção entre a verdade e a coerência do saber define a ideia como Ser. É este o alcance da doutrina das ideias para o conceito de verdade. Como Ser, a verdade e a ideia assumem o supremo significado metafísico que lhes é atribuído expressamente pelo sistema de Platão (BENJAMIN, 1984, 52).
}

Depois de conceber a verdade a partir de seu status ontológico e diferenciá-la do conhecimento, Benjamin desenvolve a relação que a verdade possui com a beleza apoiando-se na sua interpretação do Banquete de Platão. Benjamin lê nessa obra platônica a elaboração de duas teses cruciais na configuração da relação entre verdade e beleza: "a verdade é apresentada como conteúdo essencial do Belo, o reino das ideias, e a verdade é considerada bela" (BENJAMIN, 1984, 52). Segundo Benjamin, essas duas afirmações são decisivas não só para a compreensão da relação que Platão postula entre verdade e beleza como também oferecem fundamentos que ajudam a esclarecer a própria doutrina das ideias platônica como um todo. Ao comentar a segunda das afirmações, a tese de que a verdade é bela, nota-se que a interpretação de Benjamin se desvia do modo como a grande parte da tradição filosófica interpreta a relação entre verdade e beleza estabelecida por Platão no Banquete. De acordo com as interpretações mais usuais, a busca de eros pela beleza se justificaria já que a beleza seria um reflexo sensível e, portanto, de grau inferior, das ideias da verdade e do bom que, por sua vez, seriam formas puramente inteligíveis. O desejo erótico pela beleza física, tomada como sendo a manifestação sensível de grau mais baixo da própria ideia da beleza, estaria justificado na medida em que se constitui como uma via de acesso para uma ascese filosófica, passando 
pelos diversos degraus que são os estágios do impulso erótico, que aspiraria como fim último a busca pela superação do mundo sensível em direção à realidade suprema e inteligível do verdadeiro e do bom. Nesse sentido, haveria em Platão a afirmação de uma hierarquia ontológica em que o belo estaria numa relação inferior à verdade.

Benjamin, todavia, lê o Banquete sem essa hierarquia ontológica entre a beleza e a verdade. O filósofo interpreta os vários estágios do desejo erótico estabelecidos no Banquete por Platão em termos de uma descrição e não de uma justificação:

\begin{abstract}
A tese de que a verdade é bela deve ser compreendida no contexto do Symposion, que descreve os vários estágios do desejo erótico. Eros (assim devemos entender o argumento) não atraiçoa seu impulso original quando dirige sua paixão para a verdade, porque também a verdade é bela. $E$ o é não tanto em si mesma como para o Eros. (...) Assim a verdade, que é bela, não tanto em si mesma quanto para aquele que a busca (BENJAMIN, 1984, 53).
\end{abstract}

Segundo a leitura de Benjamin de Platão, o fato de a beleza da verdade estar condicionada à busca do impulso erótico, isto é, de não ser afirmada em si, mas somente em relação àquele que a busca, poderia indicar um traço de relativismo no modo como Platão descreve a relação entre verdade e beleza. Todavia, mesmo a leitura desse traço não implicaria que a tese beleza da verdade pudesse ser considerada como tendo um sentido simplesmente metafórico. Para Benjamin, a questão mais profunda problematizada pelo diálogo do Banquete diz respeito à possibilidade de a verdade fazer justiça à beleza. Benjamin aponta no Banquete a formulação desse questionamento fundamental e a resposta que Platão elabora para a questão. Segundo o filósofo, Platão responde a essa questão afirmando que a verdade garante essência à beleza uma vez que a verdade partilharia com a beleza participação no ser. É por explicitar o modo como a verdade garante o ser da beleza que Benjamin lê no diálogo platônico a descrição da "verdade como conteúdo do belo" (BENJAMIN, 1984, 53).

Assim, a relação entre verdade e beleza é entendida por Benjamin em termos de uma relação de co-pertencimento: a relação entre verdade e beleza configuraria uma relação de condicionamento mútuo e essa ligação essencial "concede beleza à verdade e, igualmente, verdade à beleza" (GAGNEBIN, 2014, 73). Nesse sentido, não 
haveria na relação entre verdade e beleza nem uma relação hierárquica, em que a beleza estaria numa posição inferior à verdade, e tampouco a afirmação de uma igualdade, como se fossem uma e a mesma coisa, mas sim o reconhecimento de uma ligação constitutiva entre verdade e beleza. Em Benjamin, por meio dessa relação entre verdade e beleza:

\begin{abstract}
Não só a beleza é redimida de sua tendência a somente pertencer ao domínio do brilho (Schein) e da aparência (Erscheinung, Schein) pela sua última ligação à verdade; também esta, a verdade, precisa por assim dizer, da beleza para ser verdadeira: a verdade não pode realmente existir sem se apresentar, se mostrar e, portanto, aparecer na história e na linguagem. Não há, então, subsunção da beleza à verdade em uma hierarquia ontológica que submete o sensível ao inteligível e o aparecer ao ser. Entre verdade e beleza haveria uma relação de co-pertencimento constitutivo como entre essência e forma (GAGNEBIN, 2014, 72).
\end{abstract}

Essa ligação constitutiva de co-pertencimento entre verdade e beleza evidencia uma característica essencial da própria verdade: "a essência da verdade como autoapresentação [Das Wesen der Wahrheit als des sich darstellenden]" (BENJAMIN, 1984, 53) [Tradução modificada]. A possibilidade de existência efetiva da verdade está relacionada à sua capacidade de apresentação, isto é, por ser capaz de apresentar a si mesma a verdade realiza a sua própria essência. Uma vez que essa essência copertence também à beleza, essa relação constitutiva entre verdade e beleza impõe a exigência de que a verdade extrapole o âmbito meramente inteligível, de abstração em si: a essência da verdade só se realiza complementarmente na apresentação. Benjamin escreve que "esse momento expositivo ou apresentativo [Darstellende Moment] da verdade é o refúgio da beleza" (BENJAMIN, 1984, 53) [Tradução modificada].

Segundo Benjamin $(1984,54)$, o estabelecimento da relação entre verdade e beleza é fundamental para impedir a identificação entre a verdade e o objeto do saber. Para o filósofo é esse o grande mérito da filosofia platônica: o de oferecer elementos capazes de evidenciar a distinção entre verdade e conhecimento. $O$ fato de Benjamin expor a configuração da relação verdade e beleza a partir de uma interpretação do Banquete não implica que Benjamin esteja compartilhando os mesmos pressupostos 
e implicações da teoria das ideias de Platão. Em seus estudos sobre o prefácio, Machado $(2004,59)$ faz um comentário esclarecedor nesse sentido: "Sem dúvida, Benjamin recorre a uma distinção entre o mundo sensível e o mundo inteligível, mas com a existência de uma abertura e uma interdependência entre ambos que supera a separação". A existência dessa abertura, abertura esta que é exposta pela ligação constitutiva que beleza e verdade possuem entre si, indicaria uma via de acesso possível e sensível para a verdade: a dependência mútua entre verdade e beleza mostra um limiar entre sensível inteligível enquanto abertura da possibilidade de um caminho para a verdade.

Se a relação entre verdade e beleza nos faz entrever essa abertura e nos indica um possível caminho, a apresentação (Darstellung) mostra como a filosofia pode ser capaz de construir esse caminho e o modo próprio do seu caminhar desviante através dele. A tarefa da filosofia seria, portanto, a elaboração desses possíveis caminhos através do laborioso exercício linguístico da apresentação. A relação entre verdade e beleza e o trabalho da apresentação colocam em evidência a dimensão propriamente estética da investigação filosófica, isto é, o caráter artístico que possui o fazer filosófico. No prefácio, Benjamin $(1984,54)$ descreve a tarefa do filósofo como tendo uma posição intermediária e mediadora entre o trabalho do investigador e do artista. O filósofo teria em comum com o investigador a tarefa de elaborar os dados empíricos através do trabalho de organização conceitual. Com o artista, o filósofo deveria partilhar a capacidade de produzir imagens: a filosofia teria em comum com o trabalho artístico justamente a tarefa da apresentação.

Haveria, nesse sentindo, um caminho de acesso à verdade que é indicado pela relação constitutiva entre verdade e beleza. Nesse caminho Benjamin expõe uma segunda relação, a relação entre a ideia e fenômeno. Para o filósofo, os conceitos exercem um papel mediador na relação entre ideias e fenômenos. Benjamin caracteriza as duas tarefas que os conceitos cumprem como sendo a salvação crítica dos fenômenos e a apresentação das ideias. Essa dupla tarefa do conceito evidencia que os conceitos intermedeiam os dois sentidos da relação entre fenômeno e ideia, isto é, tanto no sentido fenômeno-ideia quanto no sentido ideia-fenômeno. As duas tarefas que o conceito executa ocorrem de forma simultânea: 


\begin{abstract}
Graças a seu papel mediador, os conceitos permitem aos fenômenos participarem do ser das ideias. Esse mesmo papel mediador torna-os aptos para a outra tarefa da filosofia, igualmente primordial: a apresentação [Darstellung] das ideias. A redenção dos fenômenos por meio das ideias se efetua ao mesmo tempo que a apresentação [Darstellung] das ideias por meio da empiria (BENJAMIN, 1984, 56). [Tradução modificada]
\end{abstract}

Benjamin caracteriza a primeira das funções que o conceito exerce tomando como referência, mais uma vez, a teoria das ideias de Platão: a primeira tarefa do conceito é descrita em termos de salvação dos fenômenos, referência ao modo como, para Platão, os fenômenos são salvos nas ideias na medida em que participam do ser das ideias. Benjamin utiliza a ideia de participação para descrever o papel mediador exercido pelo conceito possibilitando, assim, a entrada dos fenômenos na ordem das ideias. "Mas os fenômenos não entram integralmente no reino das ideias em sua existência bruta, empírica, e parcialmente ilusória, mas apenas em seus elementos, que se salvam" (BENJAMIN, 1984, 55-56). É por esta razão que a primeira tarefa do conceito realiza dois movimentos: liberta os fenômenos de sua falsa unidade dissolvendo-os em elementos constitutivos e reúne esses elementos numa nova configuração material no conceito. Esse duplo movimento da primeira tarefa descreve o modo como o conceito consegue inserir os fenômenos, dividindo-os em elementos e reorganizando-os, na ordem das ideias: é esse processo que realiza a salvação dos fenômenos.

O primeiro desses momentos da tarefa do conceito nos mostra que os fenômenos só são salvos na medida em que são arrancados do contexto de sua existência empírica, a dissolução de seu contexto liberta-os da continuidade e unidade em que estavam presos e revela que estavam inseridos numa unidade falsa e ilusória: é somente a partir dessa destruição de seu contexto que os fenômenos se tornam livres do falso continuum das aparências e são inseridos na unidade autêntica da verdade. Ao serem retirados de seu contexto, os fenômenos são divididos e dissolvidos em seus elementos constitutivos e são esses elementos que são capazes de entrar na ordem das ideias. 
Esse primeiro movimento do conceito assinala o caráter destrutivo da sua tarefa para Benjamin. Esse aspecto destrutivo da teoria benjaminiana ganha evidência, em diversas passagens de sua obra, pelas construções imagéticas relacionadas à metáfora do fogo e do incêndio. Machado afirma que "incêndios dos envoltórios e dissolução da falsa unidade dos fenômenos são pré-requisitos para a salvação deles e descrevem o lado crítico e até mesmo destrutivo da primeira tarefa do conceito" (MACHADO, 2004, 64). É possível, nesse sentido, seguirmos o caminho realizado por Machado de evidenciar o aspecto crítico ou destrutivo do primeiro movimento da tarefa do conceito através do rastreamento de duas dessas referências metafóricas ao incêndio em Benjamin. No prefácio, no contexto das discussões da relação verdade e beleza, Benjamin recorre à metáfora do incêndio para caracterizar o modo de acesso da beleza à ordem das ideias:

\begin{abstract}
Mas não se manifesta no desvendamento e sim num processo que pode ser caracterizado metaforicamente como um incêndio, no qual o invólucro do objeto, ao penetrar na esfera das ideias, consome-se em chamas, uma destruição, pelo fogo, da obra, durante a qual sua forma atinge o ponto mais alto de sua intensidade luminosa (BENJAMIN, 1984, 53-54).
\end{abstract}

Como vimos, na medida em que verdade e beleza estão relacionadas constitutivamente, essa ligação de co-pertencimento garantiria essência à beleza pois a verdade partilharia com a beleza participação no ser, isto é, na ordem das ideias. Essa relação é descrita na afirmação da verdade como conteúdo do belo. Todavia, essa relação não implicaria na possibilidade do desvelamento da verdade enquanto manifestação do belo. No prefácio Benjamin escreve que "a verdade não é desnudamento, que aniquila o segredo, mas revelação, que the faz justiça" (BENJAMIN, 1984, 53). A relação entre verdade e beleza não torna possível o desvelamento da verdade, mas confere essência à beleza e possibilita seu acesso à ordem das ideias. Essa entrada da beleza na ordem das ideias é descrita por Benjamin pela metáfora do incêndio: a queima do invólucro ilustraria a destruição do aspecto de mera aparência necessária para garantir essência à beleza e seu acesso à ordem das ideias.

Doutoranda em Filosofia pela Universidade Federal de Goiás (UFG). Brasileira, residente em Goiânia, Goiás. E-mail: mariana.andrade.luz@gmail.com 
A primeira das tarefas do conceito descreve a relação entre fenômeno e ideia nesses mesmos termos: a função mediadora do conceito permite a participação dos fenômenos no ser das ideias por possibilitar a entrada dos fenômenos na ordem das ideias. Para cumprir essa sua tarefa de salvar os fenômenos um momento destrutivo é igualmente necessário: os fenômenos só são salvos na medida que são arrancados de seu contexto, destruindo e desmascarando a falsa unidade em que estavam inseridos e, depois, divididos e diluídos em seus elementos constitutivos. No texto das Afinidades eletivas, Benjamin descreve a relação do trabalho do comentário e da crítica por meio da referência metafórica ao fogo:

\begin{abstract}
Se, por força de um símile, quiser-se contemplar a obra em expansão como uma fogueira em chamas vívidas, pode-se dizer então que o comentador se encontra diante dela como o químico, e o crítico semelhantemente ao alquimista. Onde para aquele apenas madeira e cinzas restam como objetos de sua análise, para este tão somente a própria chama preserva um enigma: o enigma daquilo que está vivo. Assim, o crítico levanta indagações quanto à verdade cuja chama viva continua a arder sobre as pesadas achas do que foi e sobre a leve cinza do vivenciado (BENJAMIN, 2009, 13-14).
\end{abstract}

A tarefa crítica exigiria um momento destrutivo, na imagem construída por Benjamin, essa necessária destruição é ilustrada pelo modo como o fogo consome a madeira transformando-a em cinzas. Em Benjamin, o trabalho do comentário é o exame pormenorizado do teor material de uma obra: esse trabalho do comentário é relacionado analogamente à análise química da madeira e da cinza na metáfora benjaminiana da fogueira. A tarefa da crítica é a de trazer à tona o teor de verdade de uma obra a partir do seu teor material: essa relação é descrita metaforicamente como fogo. Assim, a tarefa da crítica só se cumpriria por meio da combustão do teor material e o teor de verdade seria aquilo que vem à luz pela chama produzida pelo fogo. 0 poder devastador do fogo, aquele capaz de consumir e destruir, ilustra o caráter de destruição que a tarefa crítica possui em Benjamin. Todavia, esse caráter destruidor não possui somente um sentido unilateralmente negativo em Benjamin e a própria metáfora do fogo revela a ambiguidade de seu sentido: o poder destruidor do fogo é também o poder capaz de iluminar, pela luz das chamas, e poder de transformar, já que o fogo não só consome mas transforma aquilo que toca em cinzas. 
Desse modo, ao relacionar o enigma do vivo às chamas do fogo, Benjamin está evidenciando que o âmbito da vida só pode ser compreendido em toda sua amplitude, enigmática e ambígua, através do aspecto da morte. Em Benjamin, o aspecto da destruição não remete somente ao seu sentido negativo mas figura como aquele momento em que a destruição se torna necessária se se almeja abrir a possibilidade para a reconstrução. É somente porque possui um primeiro momento destrutivo que a salvação dos fenômenos é possível. Esse movimento não se esgota na destruição, mas é através do movimento destrutivo que os elementos constitutivos dos fenômenos são reorganizados e salvos.

Os conceitos realizam a mediação entre ideia e fenômeno descrevendo uma relação de pressuposição mútua, isto é, que ocorre nos dois sentidos dessa relação. Do mesmo modo como os fenômenos necessitam das ideias para que sejam salvos, também as ideias necessitam dos fenômenos "pois elas [as ideias] não se apresentam em si mesmas, mas unicamente através de um ordenamento de elementos materiais no conceito, de uma configuração desses elementos" (BENJAMIN, 1984, 56) [Tradução modificada]. A apresentação [Darstellung] das ideias é a segunda das tarefas do conceito caracterizada por Benjamin. As ideias necessitam dos fenômenos na medida em que sua apresentação só pode ser realizada por meio da empiria. São os elementos constitutivos dos fenômenos, aqueles que foram salvos no processo descrito pela primeira tarefa, que fornecem o material necessário para a apresentação das ideias. Esses elementos constitutivos dos fenômenos são salvos na medida que são transpostos para a ordem das ideias enquanto elementos materiais na configuração dos conceitos.

Esses elementos salvos dos fenômenos que servem como elementos para a configuração material do conceito são retirados do extremo dos fenômenos. "O conceito parte do extremo" (BENJAMIN, 1984, 57) diz o filósofo. O extremo descreve aquilo que nos fenômenos não se deixa apreender por uma tentativa de classificação estrita, aqueles elementos que escapam à homogeneização, isto é, os casos que fogem à regra. Para Benjamin "as ideias só adquirem vida quando os extremos se reúnem à sua volta” (BENJAMIN, 1984, 57). É por essa razão que o filósofo rejeita a 
compreensão do universal como sendo uma espécie de média aritmética: para Benjamin, o universal é a ideia e esta só é alcançada através dos extremos.

A ênfase benjaminiana nos casos de ocorrência extrema dos fenômenos nos mostra a necessária tentativa de elaborar um modo de salvação dos fenômenos sem que estes percam a sua singularidade. Por se relacionar com os fenômenos extremos, os conceitos levam em consideração não só o que é identidade mas também as diferenças, isto é, aquilo que são as marcas singulares dos fenômenos são preservadas nas ideias. Muricy descreve o modo como Benjamin compreende a ideia afirmando que:

\begin{abstract}
A ideia, tal qual como Benjamin a concebe, é a imagem captada na escrita. Ideias são experimentos linguísticos em uma escrita que pretende redimir os fenômenos da fugacidade em que os condena ao esquecimento, sem apagála, mas incorporando-a ao texto, pela valorização formal dos pequenos detalhes, dos elementos concretos, das singularidades irredutíveis (MURICY, 1999, 24).
\end{abstract}

Benjamin afirma que a relação entre ideia e fenômeno, mediada pelo conceito através da apresentação, não é um processo de incorporação, isto é, as ideias não incorporam ou contém os fenômenos, esclarecendo que "as ideias são o seu ordenamento objetivo virtual, sua interpretação objetiva" (BENJAMIN, 1984, 56). Esse ordenamento é efetuado pela apresentação na configuração material do conceito. Para ilustrar a relação das ideias com os fenômenos Benjamin se vale de uma analogia: "As ideias se relacionam com as coisas, assim como as constelações com as estrelas" (BENJAMIN, 1984, 56). As constelações com as estrelas descrevem uma relação de configuração: através do agrupamento aparente das estrelas, formas são desenhadas e figuras visualizadas enquanto constelações. Machado interpreta essa analogia do seguinte modo:

\footnotetext{
Não se pode determinar a existência de uma estrela mediante uma dedução que parta da constelação; da mesma forma é impensável que se alcance a definição de uma constelação por indução, partindo-se das estrelas. (...) Entre os elementos (estrelas) mesmos e entre os elementos $e$ as ideias (constelações) não se encontram relações lógico-causais propriamente ditas, por isso as constelações ou configurações de ideias têm uma estrutura descontínua (MACHADO, 2004, 64-65).
}

Doutoranda em Filosofia pela Universidade Federal de Goiás (UFG). Brasileira, residente em Goiânia, Goiás. E-mail: mariana.andrade.luz@gmail.com 
Nesse sentido, a analogia nos mostra a estrutura descontínua da apresentação e a necessidade desse aspecto descontínuo marca a diferença com a estrutura contínua do procedimento lógico-matemático. A apresentação das ideias somente se realiza por meio de uma configuração descontínua e, por essa razão, difere da estrutura argumentativa dedutiva ou indutiva. A tarefa filosófica da apresentação, portanto, não se realiza através do encadeamento argumentativo contínuo e sem lacunas de ordem lógico-matemática. Através dessa analogia Benjamin põe em evidência, também, o caráter visual e imagético da tarefa da apresentação na elaboração, por meio do conceito, de uma configuração material para as ideias. A apresentação [Darstellung] das ideias é descrita por Benjamin $(1984,56)$ como o tornar presente da ideia através da configuração material do conceito. O vocábulo utilizado por Benjamin (BENJAMIN, 1991a, 214) é vergegenwärtigt', que poderia ser traduzido como "presentificar" ou "tornar presente", remetendo ao sentido de tornar presente na forma. Desse modo, para o filósofo, a ideia é uma forma linguística na medida que é elaborada, pela apresentação, através do exercício da forma na linguagem.

A importância conferida por Benjamin à questão da apresentação está relacionada a uma defesa do caráter linguístico e de expressão do exercício do pensamento filosófico: o filósofo constrói sua filosofia a partir desse resgate da essência linguística do pensamento filosófico. A centralidade da questão da apresentação (Darstellung) põe em evidência as relações profundas e recíprocas entre pensamento e linguagem e entre a forma de apresentação e a elaboração do pensamento filosófico. A ênfase no caráter apresentativo ou expositivo da filosofia, em Benjamin, está atrelada à defesa de que o pensamento se realiza e se elabora durante

\footnotetext{
${ }^{8}$ Os tradutores da obra de Benjamin vertem a passagem de maneira distintas. Rouanet (BENJAMIN, 1984, p. 56) traduz como "atualiza" e, Osborne, tradutor para o inglês, utiliza a expressão "lend it actuality” (BENJAMIN, 2003, 34), ambos, portanto, remetem vergegenwärtigen ao sentido de atualizar. Este verbo pode ser igualmente traduzido por representar, figurar e tornar presente. Barrento (BENJAMIN, 2013, 22) usa "presentificar" e Pivetta (BENJAMIN, 2012, 68) verte para o espanhol como "hace presente", relacionando, igualmente, ao sentido de tornar presente. Seguimos, assim, a opção de Barrento e Pivetta, pois, no contexto específico, parece-nos mais adequado.
}

Doutoranda em Filosofia pela Universidade Federal de Goiás (UFG). Brasileira, residente em Goiânia, Goiás. E-mail: mariana.andrade.luz@gmail.com 
o próprio processo de sua apresentação escrita, através de um exercício de expressividade linguística. A verdade, portanto, só pode ser pensada relacionada à linguagem e ao caráter propriamente histórico de sua constituição e nunca como um puro ou simples pensamento. Na filosofia não existe pensamento puro ou simples que possa ser concebido fora ou desatrelado da sua forma própria de apresentação escrita. O pensamento filosófico só se realiza enquanto texto, através da elaboração do pensamento no exercício da escrita e na sua forma de apresentação. Se lembrarmos a relação etimológica entre as palavras texto e tecido ${ }^{9}$, em grego e em latim, poderíamos dizer que o exercício filosófico se nutre da possibilidade sempre renovada do entrelaçamento de seus fios e toma sua força, o fôlego incansável do pensamento, do esforço expressivo capaz de tecer sempre novos arranjos: na tentativa de construir novas e diferentes figuras e imagens.

\section{REFERÊNCIAS}

BENJAMIN, Walter. Erkenntniskritische Vorrede. In: Ursprung des deutschen Trauerspiels - Gesammelte Schriften. Band I-Tiel I. Frankfurt: Suhrkamp, 1991a. pp. 207-238.

Questões introdutórias de crítica do conhecimento. In__: Origem do drama barroco alemão. Tradução de Sergio Paulo Rouanet. São Paulo: Brasiliense, 1984. pp. 49-79.

9 No ensaio $A$ imagem de Proust, Benjamin faz alusão ao parentesco etimológico entre texto e tecido na passagem em que escreve "Se texto significa para os romanos, aquilo que se tece (...)" e utiliza a referência metafórica ao tecido e à tapeçaria ao servir-se da imagem do trabalho de costura de Penélope. Cf. BENJAMIN, 1994, p. 37.

Doutoranda em Filosofia pela Universidade Federal de Goiás (UFG). Brasileira, residente em Goiânia, Goiás. E-mail: mariana.andrade.luz@gmail.com 
Prólogo epistemológico-crítico. In_: Origem do drama trágico alemão. Tradução de João Barrento. 2 ed. Belo Horizonte: Autêntica, 2013. pp. 15-47.

. Epistemo-critical Prologue. In_: The origin of German tragic drama. Translated by John Osborne. London, New York: Verso, 2003. pp. 27-56.

. Palabras preliminares sobre critica del conhecimento. In_: Origen del trauerspiel alemán. Traducción de Carola Pivetta. Buenos Aires: Ediciones Gorla, 2012. pp. 61-93.

. Goethes Wahlverwandtschaften. In_: Gesammelte Schriften. Band I-Tiel I. Frankfurt: Suhrkamp, 1991b. pp. 123-201.

. As afinidades eletivas de Goethe. In _ : Ensaios reunidos: escritos sobre Goethe. Tradução de Mônica K. Bornbusch. São Paulo: Duas Cidades; Ed. 34, 2009. pp. 11-121.

. A imagem de Proust. In_: Magia e Técnica, Arte e Política - Obras Escolhidas I. Tradução de Sergio Paulo Rouanet. $7^{\underline{a}}$ ed. São Paulo: Brasiliense, 1994, pp. 36-49.

DAMIÃO, Carla Milani. Anti-classicismo, mística judaica, símbolo e alegoria.

Cadernos Benjaminianos, Número especial, Belo Horizonte, 2013, pp. 55-69.

GAGNEBIN, Jeanne Marie. Do conceito de Darstellung em Walter Benjamin (ou Verdade e beleza). In__: Limiar, aura e rememoração. São Paula: Editora 34, 2014. pp. 63-73.

. Comentário filológico e crítica materialista. Trans/Form/Ação, 2011, vol. 34, n. 2, pp. 137-154.

GATTI, Luciano. Constelações: Crítica e Verdade em Benjamin e Adorno. São Paulo: Edições Loyola, 2009.

KANGUSSU, Imaculada. Walter Benjamin e Kant I. Inexprimível: A herança do "sublime" na filosofia de Walter Benjamin. In: Márcio Seligmann-Silva (Org.). Leituras de Walter Benjamin. São Paulo: FAPESP/Anna Blume, 1999a. pp. 147156.

. Walter Benjamin e Kant II. Twilight Zone: O lugar da beleza em Kant \& Benjamin. In: Márcio Seligmann-Silva (Org.). Leituras de Walter Benjamin. São Paulo: FAPESP/Anna Blume, 1999b. pp. 161-172.

MACHADO, Francisco de Ambrosis Pinheiro. Imanência e história: crítica do conhecimento em Walter Benjamin. Belo Horizonte: Ed.UFMG, 2004.

Doutoranda em Filosofia pela Universidade Federal de Goiás (UFG). Brasileira, residente em Goiânia, Goiás. E-mail: mariana.andrade.luz@gmail.com 
MENNINGHAUS, Winfried: Saber de los umbrales. Walter Benjamin y el pasaje del mito. Traducción de Mariela Vargas y Martín de Bielke. Buenos Aires: Biblos, 2013.

MURICY, Katia. Alegorias da Dialética: imagem e pensamento em Walter Benjamin. Rio de Janeiro: Relume Dumará, 1999.

WOOLF, Virginia. As ondas. Tradução de Lya Luft. Rio de Janeira: Nova fronteira, 1980. 